\title{
Pesquisa qualitativa na produção científica do campo da bioética
}

\author{
Qualitative research into the scientific production \\ in the field of bioethics
}

Carlos Dimas Martins Ribeiro

Ivia Maksud ${ }^{1}$

Lenita Barreto Lorena Claro

Julio Wong Un ${ }^{1}$

${ }^{1}$ Instituto de Saúde

Coletiva, Universidade

Federal Fluminense. R.

Marques do Paraná 303/2

andar/anexo do Hospital

Antônio Pedro, Centro.

24.033-900 Niterói RJ

Brasil.

dimasmribeiro@gmail.com
Abstract This article discusses the character and use of qualitative research methods in the field of bioethics. A systematic review of articles published in Latin American countries and selected from the SciELO database was conducted, with special emphasis on articles that employed qualitative research methodology. The set of articles reveals a field of bioethics composed of three distinct vectors. The first refers to the dual characterization of bioethics that can be defined as a social movement or as a discipline; the second differentiates bioethics from other fields of ethics, especially from predominantly deontology-based professional ethics; and the third is related to ethical approaches adopted in the analyses conducted in the research. A relatively insignificant part of these texts result from qualitative research and they can be divided into four categories according to their themes and guidelines: bioethics as a field and/or discourse; training in health; ethics, care, and clinical practice; formulation of health policy. The production shows, on the one hand, a relatively timid approach of social science researchers to the field of bioethics and, on the other hand, little use of qualitative methodologies in research in the field and, in some cases, a certain lack of precision regarding use of the methods.

Key words Bioethics, Qualitative research, Health
Resumo Este artigo objetiva discutir o caráter e a utilização dos métodos de pesquisa qualitativa no campo da bioética. Realizou-se revisão sistemática de artigos publicados em países da América Latina, selecionados a partir da base Scielo, com especial ênfase para aqueles que empregaram metodologia qualitativa de pesquisa. O conjunto dos artigos revela um campo da bioética conformado a partir de três vetores de distinção. O primeiro refere-se à dupla caracterização da bioética que pode ser definida como um movimento social ou como uma disciplina; o segundo opera diferenciando a bioética de outros campos da ética, em particular com a profissional de base predominantemente deontológica; o terceiro está relacionado às abordagens éticas adotadas nas análises empreendidas nas pesquisas. Parte pouco expressiva desses textos resulta de pesquisas qualitativas e podem ser divididos em quatro eixos de acordo com seus temas e orientações: bioética como campo elou discurso; formação em saúde; ética, assistência e prática clínica; formulação de política de saúde. Esta produção revela, por um lado, uma tímida aproximação de pesquisadores das Ciências Sociais ao campo da bioética e, por outro, pouca utilização/apropriação de metodologias qualitativas, e, ainda, em alguns casos, certa imprecisão quanto ao uso de métodos.

Palavras-chave Bioética, Pesquisa qualitativa, Saúde 


\section{Introdução}

Nascida na década de 70 nos Estados Unidos, a bioética expande-se pela Europa na década de 80 e pela América Latina na de $90^{1}$. Ao contrário da bioética norte-americana que se concentrou na análise dos conflitos éticos no âmbito da clínica, na Europa a ênfase foi colocada nos Direitos $\mathrm{Hu}-$ manos e, na América Latina, buscou-se vinculála ao contexto da região, caracterizado pelas grandes desigualdades sociais e o fracasso das políticas neoliberais. Desta forma, o desenvolvimento da bioética na América Latina caracterizou-se, inicialmente, na década de 80 , pela assimilação predominante da bioética biomédica com enfoque principialista, e, para numa etapa seguinte, na década de 90, voltar-se não apenas para as preocupações éticas relacionadas aos problemas emergentes vinculados ao desenvolvimento da tecnologia biomédica, mas também aos problemas persistentes, relativos à pobreza e exclusão social, nos quais o princípio da justiça adquire relevância $^{1}$. Merece destaque a realização, no Brasil, do VI Congresso Mundial de Bioética, em 2002, cujo tema central foi Bioética: poder e injustiça.

A multiplicidade de abordagens teóricas e práticas da bioética pode ser observada na América Latina, como no Brasil. No Brasil, podemos enumerar a Bioética da Reflexão Autônima, a Bioética de Intervenção, a Bioética de Proteção (Brasil e Chile), a Bioética da Teologia da Libertação, a Bioética Feminista e Antirracista e a Bioética Crítica de Inspiração Feminista ${ }^{2}$. Na avaliação de alguns autores ${ }^{2}$, destacam-se, nestas correntes da bioética brasileira, a preocupação ética com "a proteção dos mais frágeis e o papel do Estado nesta tarefa, a despeito da relevância conferida à sociedade civil; a pluralidade moral aliada a uma bioética laica, sem pressupostos religiosos; e, por fim, o respeito à dignidade da pessoa humana embasada nos direitos humanos como limites inegociáveis para práticas sociais".

Pesquisadores vinculados ao campo da Saúde Coletiva e da Bioética têm realizado, de forma cada vez mais ampla, pesquisas qualitativas, a partir do emprego de diversos métodos e técnicas, utilizadas isoladamente ou de forma complementar, como observação participante, observação direta, utilização de caderno ou anotações de campo, variadas formas de entrevistas, grupos focais, registro de fotografias ou vídeos, levantamento e análise de textos ou documentos, distintos modos de análise de discurso etc. ${ }^{3-5}$. Este artigo visa contribuir para o debate sobre a interface entre os estudos do campo da bioética e as pesquisas qualitativas. Nesse sentido, pretende discutir o caráter e a utilização dos métodos de pesquisa qualitativa em estudos situados no campo da bioética. Para tanto, examinamos a literatura produzida nos últimos anos na América Latina.

\section{Metodologia}

O método utilizado consistiu em revisão sistemática de todos os artigos publicados em países da América Latina, disponíveis na base Scielo até 31 de outubro de 2010, selecionados a partir do descritor "bioética". Foram encontrados 462 artigos. A pesquisa foi dividida em duas etapas. Na primeira delas, utilizamos um instrumento para a coleta de dados e sistematização dos artigos, composto pelos seguintes itens: a área do periódico, os principais temas abordados e os objetivos pretendidos. Deste total de 462 artigos, oito foram excluídos porque não abordavam o referido tema (i.e, o termo bioética foi utilizado nesses artigos excluídos apenas em função do fato de que os projetos de pesquisa foram enviados a comitês de ética ou bioética), resultando em 454 textos. Essa primeira etapa visava permitir uma visão geral das publicações no campo da bioética.

$\mathrm{Na}$ segunda etapa, foram selecionados, deste total de 454 artigos, os que empregaram metodologia/métodos qualitativos de pesquisa, o que resultou num conjunto de 33 artigos (Quadro 1).

Esta etapa da pesquisa consistiu de análise aprofundada dos artigos que, de alguma forma, se encaixavam sob o signo de pesquisa qualitativa. Para analisar esse conjunto, construímos um segundo instrumento, contendo os seguintes itens: a origem e o perfil dos autores, o tipo de artigo, os objetivos, a concepção de bioética e os referenciais utilizados, a população estudada, as ferramentas metodológicas utilizadas e informações sobre a submissão a comitês de ética em pesquisa.

\section{Resultados e discussão}

Análise da primeira etapa:

o campo da bioética na América Latina

Os 454 trabalhos, obtidos na primeira etapa, foram classificados de acordo com o tipo de artigo (Tabela 1), observando-se que predominaram aqueles voltados para a reflexão sobre temas práticos, presentes no cotidiano do traba- 
Quadro 1. Referências dos artigos analisados.

\begin{tabular}{|c|c|c|c|}
\hline $\mathbf{N}^{\mathbf{0}}$ & Autor & Título & Revista \\
\hline 1 & Alvarez-Diaz JA6. & $\begin{array}{l}\text { Un estudio exploratorio sobre la donación } \\
\text { hipotética de embriones humanos en Chile. }\end{array}$ & $\begin{array}{l}\text { An Med Interna (Madrid) } \\
\text { 2007; 24(12):579-584. }\end{array}$ \\
\hline 2 & $\begin{array}{l}\text { Amorim AG, Souza } \\
\mathrm{ECF}^{7} \text {. }\end{array}$ & $\begin{array}{l}\text { Problemas éticos vivenciados por dentistas: } \\
\text { dialogando com a bioética para ampliar o olhar } \\
\text { sobre o cotidiano da prática profissional. }\end{array}$ & $\begin{array}{l}\text { Cien Saude Colet 2010; } \\
\text { 15(3):869-878. }\end{array}$ \\
\hline 3 & $\begin{array}{l}\text { Coli RCP, Anjos MF, } \\
\text { Pereira } \mathrm{LL}^{8} \text {. }\end{array}$ & $\begin{array}{l}\text { The Attitudes of Nurses from an Intensive Care } \\
\text { Unit in the Face of Errors: an Approach in } \\
\text { Light of Bioethics. }\end{array}$ & $\begin{array}{l}\text { Rev Latino-Am } \\
\text { Enfermagem 2010; } \\
18(3): 324-330\end{array}$ \\
\hline 4 & Costa SIF, Diniz D9. & Mídia, clonagem e bioética. & $\begin{array}{l}\text { Cad Saude Publica 2000; } \\
\text { 16(1):155-162. }\end{array}$ \\
\hline 5 & $\begin{array}{l}\text { Fagundes MJD, Soares } \\
\text { MGA, Diniz NM, Pires } \\
\text { JR, Garrafa V }{ }^{10} \text {. }\end{array}$ & $\begin{array}{l}\text { Análise bioética da propaganda e publicidade de } \\
\text { medicamentos. }\end{array}$ & $\begin{array}{l}\text { Cien Saude Colet 2007; } \\
\text { 12(1):221-229. }\end{array}$ \\
\hline 6 & $\begin{array}{l}\text { Ferreira FC, Nichiata } \\
\text { LYI }^{11} \text {. }\end{array}$ & $\begin{array}{l}\text { Mulheres vivendo com aids e os profissionais do } \\
\text { Programa Saúde da Família: revelando o } \\
\text { diagnóstico. }\end{array}$ & $\begin{array}{l}\text { Rev Esc Enferm 2008; } \\
42(3): 483-489 .\end{array}$ \\
\hline 7 & Fortes $\mathrm{PAC}^{12}$. & $\begin{array}{l}\text { A equidade no sistema de saúde na visão de } \\
\text { bioeticistas brasileiros. }\end{array}$ & $\begin{array}{l}\text { Rev Assoc Med Bras 2010; } \\
56(1): 47-50 \text {. }\end{array}$ \\
\hline 8 & Fortes $\mathrm{PAC}^{13}$. & $\begin{array}{l}\text { Bioeticistas brasileiros e os princípios da } \\
\text { universalidade e da integralidade no SUS. }\end{array}$ & $\begin{array}{l}\text { Rev Saude Publica 2009; } \\
\text { 43(6):1054-1058. }\end{array}$ \\
\hline 9 & Fracapani $\mathrm{M}$, Fazio $\mathrm{M}^{14}$. & $\begin{array}{l}\text { El portafolio como estrategia de evaluación en } \\
\text { carreras de posgrado inter y transdisciplinarias. }\end{array}$ & $\begin{array}{l}\text { Acta Bioeth 2008; } \\
14(1): 68-73 \text {. }\end{array}$ \\
\hline 10 & $\begin{array}{l}\text { Garbin CAS, Gonçalves } \\
\text { PE, Garbin AJI, } \\
\text { Moimaz SAS }{ }^{15} \text {. }\end{array}$ & $\begin{array}{l}\text { Evaluación de las metodologías de enseñanza- } \\
\text { aprendizaje de la bioética en las facultades de } \\
\text { odontología brasileñas. }\end{array}$ & $\begin{array}{l}\text { Educ Méd 2009; } \\
\text { 12(4):231-237. }\end{array}$ \\
\hline 11 & $\begin{array}{l}\text { Garrafa V, Albuquerque } \\
\mathrm{MC}^{16} \text {. }\end{array}$ & $\begin{array}{l}\text { Enfoque bioético de lacomunicación en la } \\
\text { relación médico-paciente en las unidades de } \\
\text { terapia intensiva pediátricas. }\end{array}$ & $\begin{array}{l}\text { Acta Bioeth 2001; } \\
7(2): 355-367\end{array}$ \\
\hline 12 & $\begin{array}{l}\text { Gonçalves PE, Saliba } \\
\text { Garbin CA, Isper } \\
\text { Garbin AJ, Adas Saliba } \\
\mathrm{N}^{17} \text {. }\end{array}$ & $\begin{array}{l}\text { Análise qualitativa do conteúdo ministrado na } \\
\text { disciplina de bioética nas faculdades de } \\
\text { odontologia brasileiras. }\end{array}$ & $\begin{array}{l}\text { Acta Bioeth 2010; } \\
\text { 16(1):70-76. }\end{array}$ \\
\hline 13 & $\begin{array}{l}\text { Griboski RA, Guilhem } \\
\mathrm{D}^{18} \text {. }\end{array}$ & $\begin{array}{l}\text { Mulheres e profissionais de saúde: o imaginário } \\
\text { cultural na humanização ao parto e nascimento. }\end{array}$ & $\begin{array}{l}\text { Texto Contexto - Enferm } \\
2006 ; 15(1): 107-114 .\end{array}$ \\
\hline 14 & Guerra RA ${ }^{19}$. & Bioética en la malla curricular de odontología. & $\begin{array}{l}\text { Acta Bioeth 2006; } \\
\text { 12(1):49-54. }\end{array}$ \\
\hline 15 & $\begin{array}{l}\text { Halac J, Halac E, Moya } \\
\text { MP, Olmas JM, Dopazo } \\
\text { SL, Dolagaray } \mathrm{N}^{20} \text {. }\end{array}$ & $\begin{array}{l}\text { Bioética perinatal: ¿Eutanasia o decisiones sobre } \\
\text { terminación de la vida?: Análisis del Protocolo } \\
\text { de Groningen. }\end{array}$ & $\begin{array}{l}\text { Arch Argent Pediatr } \\
2009 ; 107(6): 520-526 .\end{array}$ \\
\hline
\end{tabular}




\begin{tabular}{|c|c|c|c|}
\hline $\mathrm{N}^{\circ}$ & Autor & Título & Revista \\
\hline 16 & Irrazabal G ${ }^{21}$. & $\begin{array}{l}\text { Bioética y catolicismo: dificultades en torno a la } \\
\text { constitución de una identidad colectiva. }\end{array}$ & $\begin{array}{l}\text { Relig Soc 2010; } \\
\text { 30(1):101-116. }\end{array}$ \\
\hline 17 & Irrazabal G G $^{22}$. & $\begin{array}{l}\text { El derecho al aborto en discusión: la } \\
\text { intervención de grupos católicos en la comisión } \\
\text { de salud de la legislatura de la ciudad de Buenos } \\
\text { Aires. }\end{array}$ & $\begin{array}{l}\text { Sociologias 2010; } \\
12(24): 308-336\end{array}$ \\
\hline 18 & $\begin{array}{l}\text { Kalamatianos PA, } \\
\text { Narvai } \mathrm{PC}^{23} \text {. }\end{array}$ & $\begin{array}{l}\text { Aspectos éticos do uso de produtos fluorados no } \\
\text { Brasil: uma visão dos formuladores de políticas } \\
\text { públicas de saúde. }\end{array}$ & $\begin{array}{l}\text { Cien Saude Colet 2006; } \\
\text { 11(1):63-69. }\end{array}$ \\
\hline 19 & $\begin{array}{l}\text { Mascarenhas NB, Santa } \\
\text { Rosa } \mathrm{DO}^{24} \text {. }\end{array}$ & $\begin{array}{l}\text { Ensino da bioética na formação do enfermeiro: } \\
\text { interface com a bibliografia adotada. }\end{array}$ & $\begin{array}{l}\text { Acta Paul Enferm 2010; } \\
\text { 23(3):392-398. }\end{array}$ \\
\hline 20 & $\begin{array}{l}\text { Mashiri Z, Elizabeth } \\
\mathrm{C}^{25} \text {. }\end{array}$ & $\begin{array}{l}\text { Los comités de ética de investigación biomédica } \\
\text { y psicosocial en Bolivia. }\end{array}$ & $\begin{array}{l}\text { Acta Bioeth 2010; } \\
\text { 16(1):87-91. }\end{array}$ \\
\hline 21 & $\begin{array}{l}\text { Mondragon L, Monroy } \\
\text { Z, Ito ME, Medina- } \\
\text { Mora } \mathrm{ME}^{26} \text {. }\end{array}$ & $\begin{array}{l}\text { Disyuntivas en las concepciones sobre } \\
\text { autonomía y beneficencia que afectan la } \\
\text { terapéutica del intento suicida. }\end{array}$ & $\begin{array}{l}\text { Acta Bioeth 2010; } \\
\text { 16(1):77-86. }\end{array}$ \\
\hline 22 & Peláez F, Rosa Z Z & $\begin{array}{l}\text { La bioética: ética del cuidado de la vida y la salud } \\
\text { para el desarrollo humano. }\end{array}$ & $\begin{array}{l}\text { Hacia Promoc Salud } \\
\text { 2009; 14(2):76-93. }\end{array}$ \\
\hline 23 & $\begin{array}{l}\text { Santiago MMA, } \\
\text { Palácios } \mathrm{M}^{28} \text {. }\end{array}$ & $\begin{array}{l}\text { Temas éticos e bioéticos que inquietaram a } \\
\text { Enfermagem: publicaçôes da REBEn de 1970- } \\
2000 .\end{array}$ & $\begin{array}{l}\text { Rev Bras Enferm 2006; } \\
\text { 59(3):349-353. }\end{array}$ \\
\hline 24 & $\begin{array}{l}\text { Schonhaut-Berman L, } \\
\text { Millan-Klusse T, } \\
\text { Hanne-Altermatt } \mathrm{C}^{29} \text {. }\end{array}$ & $\begin{array}{l}\text { Competencias transversales en la formación de } \\
\text { especialistas en pediatría, Universidad de Chile. }\end{array}$ & $\begin{array}{l}\text { Educ Méd 2009; } \\
\text { 12(1):33-41. }\end{array}$ \\
\hline 25 & Selli L, Garrafa V ${ }^{30}$. & $\begin{array}{l}\text { Bioética, solidariedade crítica e voluntariado } \\
\text { orgânico. }\end{array}$ & $\begin{array}{l}\text { Rev Saude Publica 2005; } \\
\text { 39(3):473-478. }\end{array}$ \\
\hline 26 & $\begin{array}{l}\text { Selli L, Garrafa V, } \\
\text { Junges JR }{ }^{31} \text {. }\end{array}$ & $\begin{array}{l}\text { Beneficiários do trabalho voluntário: uma } \\
\text { leitura a partir da bioética. }\end{array}$ & $\begin{array}{l}\text { Rev Saude Publica 2008; } \\
\text { 42(6):1085-1089. }\end{array}$ \\
\hline 27 & $\begin{array}{l}\text { Silva RP, Ribeiro } \\
\mathrm{VMB}^{32} \text {. }\end{array}$ & $\begin{array}{l}\text { Inovação curricular nos cursos de graduação em } \\
\text { medicina: o ensino da bioética como uma } \\
\text { possibilidade. }\end{array}$ & $\begin{array}{l}\text { Rev Bras Educ Med 2009; } \\
\text { 33(1):134-143. }\end{array}$ \\
\hline 28 & Tamanini $\mathrm{M}^{33}$. & $\begin{array}{l}\text { Novas tecnologias reprodutivas conceptivas: } \\
\text { bioética e controvérsias. }\end{array}$ & $\begin{array}{l}\text { Rev Estud Fem 2004; } \\
\text { 12(1):73-107. }\end{array}$ \\
\hline 29 & $\begin{array}{l}\text { Taquette SR, Rego S, } \\
\text { Schramm SR, Soares } \\
\text { LL, Carvalho SV }\end{array}$ & $\begin{array}{l}\text { Situações eticamente conflituosas vivenciadas } \\
\text { por estudantes de medicina. }\end{array}$ & $\begin{array}{l}\text { Rev Assoc Med Bras 2005; } \\
\text { 51(1):23-28. }\end{array}$ \\
\hline 30 & Vasconcelos FAG ${ }^{35}$. & $\begin{array}{l}\text { Fome, solidariedade e ética: uma análise do } \\
\text { discurso da Ação da Cidadania contra a Fome, a } \\
\text { Miséria e pela Vida. }\end{array}$ & $\begin{array}{l}\text { Hist Cienc Saude- } \\
\text { Manguinhos 2004; } \\
\text { 11(2):259-277. }\end{array}$ \\
\hline
\end{tabular}




Quadro 1. continuação
\begin{tabular}{|l|l|l|l|}
\hline$N^{\mathbf{0}}$ & \multicolumn{1}{|c|}{ Autor } & \multicolumn{1}{c|}{ Título } & \multicolumn{1}{c|}{ Revista } \\
\hline 31 & Wainer $\mathrm{R}^{36}$. & $\begin{array}{l}\text { Acompañando a la gente en el último } \\
\text { momento de su vida: reflexiones en torno a la } \\
\text { construcción paliativista de la dignidad en el } \\
\text { final de la vida. }\end{array}$ & Runa 2011; 28:111-140. \\
\hline 32 & Zoboli ELCP ${ }^{37}$. & $\begin{array}{l}\text { Enfermeiros e usuários do Programa Saúde da } \\
\text { Família: contribuições da bioética para } \\
\text { reorientar esta relação profissional. }\end{array}$ & $\begin{array}{l}\text { Acta Paul Enferm 2007; } \\
\text { 20(3):316-320. }\end{array}$ \\
\hline 33 & $\begin{array}{l}\text { Zoboli ELCP, Fortes } \\
\text { PAC }{ }^{38} .\end{array}$ & $\begin{array}{l}\text { Bioética e atenção básica: um perfil dos } \\
\text { problemas éticos vividos por enfermeiros e } \\
\text { médicos do Programa Saúde da Família, São } \\
\text { Paulo, Brasil. }\end{array}$ & $\begin{array}{l}\text { Cad Saude Publica 2004; } \\
\text { 20(6):1690-1699. }\end{array}$ \\
\hline
\end{tabular}

Tabela 1. Classificação do total de artigos obtidos por tipo de artigo.

\begin{tabular}{lrc}
\hline \multicolumn{1}{c}{ Tipos de Artigos } & $\begin{array}{r}\text { Frequência } \\
\text { Absoluta }\end{array}$ & $\begin{array}{r}\text { Frequência } \\
\text { Percentual }\end{array}$ \\
\hline Discussão sobre um Tema Prático ou Relato de Experiência & 175 & $38,5 \%$ \\
Reflexão Teórico-Conceitual & 82 & $18,1 \%$ \\
Reflexão ou Contribuição ao Ensino, Formação Profissional ou Currículos & 33 & $7,3 \%$ \\
Pesquisa Empírica com Método Qualitativo & 33 & $7,3 \%$ \\
Pesquisa Empírica com Método Quantitativo & 30 & $6,6 \%$ \\
Revisão da Literatura & 21 & $4,6 \%$ \\
Reflexão sobre Ética na Prática Profissional & 12 & $2,6 \%$ \\
Outros (editorial, opinião) & 68 & $15,0 \%$ \\
Total & $\mathbf{4 5 4}$ & $\mathbf{1 0 0} \%$ \\
\hline
\end{tabular}

lho em saúde, e para discussão de casos clínicos interessantes ou impactantes sob o ponto de vista da bioética. A seguir, encontram-se os trabalhos dedicados à reflexão teórico-conceitual do campo e os editoriais, artigos de opinião, agrupados sob a rubrica "outros". Com frequência semelhante, foram encontrados artigos voltados para a formação profissional, os que relatavam estudos empíricos utilizando métodos quantitativos e os que utilizaram métodos qualitativos.

Essa visão panorâmica destaca a busca predominante da bioética para a reflexão e discussão de situações e temas práticos, que se configuram em impasses para a prática profissional. Isso mostra a relevância que o estudo da bioética tem para a formação dos profissionais de saúde, preparando-os para o enfrentamento dessas situações, que se diversificam e adquirem maior com- plexidade com o uso de novas tecnologias na área da saúde.

O campo da bioética, tal como apresentado nesse conjunto maior de artigos, pode ser traçado a partir de três vetores de distinção. O primeiro refere-se à caracterização da bioética predominantemente como uma disciplina acadêmica. Desta forma, a bioética é entendida como uma "ética aplicada às ciências da vida", de natureza interdisciplinar ou multidisciplinar, conforme expressa um dos artigos analisados ${ }^{39,40}$.

Para alguns artigos pesquisados, a bioética tem uma dupla tarefa: a descritiva e a normativa. A primeira tem como objetivo "identificar e caracterizar os problemas éticos que emergem na atenção à saúde", constituindo-se em uma tarefa científica e não filosófica, conforme salienta um dos artigos analisados ${ }^{38}$. A segunda relaciona-se 
à sua capacidade de dar respostas aos conflitos ou dilemas éticos decorrentes dos avanços técnico-científicos ou "produzir modelos teóricos metodológicos para auxiliar a tomada de decisão ética no campo da saúde", na expressão de outro artigo incluído na pesquisa ${ }^{41}$.

Uma maneira de conceber esta dupla tarefa da bioética pode ser encontrada no procedimento de justificação moral - denominado equilíbrio reflexivo - empregado por John Rawls no seu livro A Theory of Justice, publicado pela primeira vez em $1971^{42}$. O equilíbrio reflexivo pode ser caracterizado como um processo de ajustamento ou apoio mútuo entre um conjunto de crenças morais e não morais, o mais amplo possível, que se pode dizer relevante para desenvolver uma teoria moral - ou de justiça, como fez Rawls - para selecionar princípios éticos ou para decidir sobre problemas práticos ${ }^{43}$. A qualidade deste processo pode ser avaliada tanto em relação ao próprio processo reflexivo - no sentido de saber se ele merece este termo - quanto em relação ao produto resultante, que tem como um dos seus principais componentes a coerência. Trata-se de um processo que não objetiva produzir certezas, mas testar algumas crenças em contraste com outras, como estratégia para justificar ou oferecer razões para um comportamento considerado ético, que configura um equilíbrio sempre instável ou provisório, permanentemente aberto a revisões.

Embora o método do equilíbrio reflexivo pretenda ser o mais inclusivo possível em relação às crenças que serão levadas em consideração na análise, para que possa ser trabalhável e atender a propósitos investigativos específicos, pode ser necessário selecionar os tipos de crenças, argumentos e requerimentos metodológicos que serão incluídos, a depender das questões em jogo ${ }^{43}$. Desta forma, Daniels ${ }^{44}$ distingue um equilíbrio reflexivo amplo de um limitado, sendo que, neste último caso, o processo se dá entre os julgamentos morais sobre situações particulares e os princípios éticos gerais que se somam a estes julgamentos de modo relevante, num processo de ida e volta entre princípios e julgamentos.

Esta última perspectiva pode ser promissora para as análises de conflitos éticos, utilizando-se a abordagem qualitativa de investigação no campo da bioética. Como observa Kleinman ${ }^{45}$,"para o etnógrafo, a experiência ordinária é a base social da condição humana", entendendo experiência como o "fluir das interações diárias no mundo local". Para este autor ${ }^{45}$, "no nível da experiência social, a moral é definida pelo processo lo- cal concernente aos valores vividos". Desta forma, "enquanto a experiência moral é sempre sobre engajamento prático em um mundo local particular, um espaço cultural que agrega especificidades políticas, econômicas e psicológicas", o discurso ético é elaborado do ponto de vista de uma articulação abstrata sobre valores translocais ou passíveis de serem - mantidas todas as condições - universalizáveis ${ }^{45}$.

Para Kleinman ${ }^{45}$, a distinção entre processo moral e discurso ético é fundamental, não apenas para "ver a utilidade da perspectiva translocal quando nos confrontamos" com práticas locais condenáveis - a linguagem dos direitos humanos, por exemplo, ocupa esta função -, mas também porque o próprio mundo local pode oferecer posições morais relevantes e alternativas ao discurso ético. Nesta perspectiva, o método do equilíbrio reflexivo é um processo que pode ser utilizado para análises no campo da pesquisa qualitativa em bioética, produzindo um ajustamento mútuo entre o discurso moral dos sujeitos sociais relativo aos processos locais e às teorias éticas utilizadas nestas análises, de forma que, tanto um como outro, possam ser passíveis de crítica e enriquecimento.

O segundo vetor de distinção opera diferenciando a bioética de outros campos da ética, em particular com a ética profissional de base predominantemente deontológica, que antecedeu o surgimento da bioética. Enquanto a ética profissional restringia-se aos problemas morais no campo das profissões da saúde, a bioética abarcaria um universo maior representado pelas reflexões éticas, profissionais ou não, relativas à saúde e à vida.

A origem da bioética é imputada, pela maioria dos artigos analisados, a Van Renssenlaer Potter, ao publicar, em 1971, sua obra Bioethics: bridge to the future, embora também sejam mencionados Andre Hellegers, que no mesmo ano fundou o The Kennedy Institute of Ethic, $e$ Fritz Jahn, que teria utilizado o termo bioethics pela primeira vez, em 1927, conforme um dos artigos ${ }^{46}$.

Contudo, as duas primeiras fontes teóricas foram as principais responsáveis pelo surgimento e desenvolvimento da bioética, representando uma importante guinada ética no campo da saúde, em relação a da médica hipocrática, hegemônica até esse momento ${ }^{47}$. Esta guinada representa a falha de um princípio fundamental da moral tradicional - o Princípio da Sacralidade da Vida (PSV) -, que durante séculos tem guiado a prática médica, e a emergência do Princípio da Qualidade de Vida (PQV). De modo geral, enquanto 
que para o PSV deve-se respeitar a vida humana como valor absoluto, não podendo ser tirada sob nenhuma circunstância e não se devendo intervir nos processos teleológicos da ordem natural, o PQV sustenta que a vida só tem valor se provida de determinadas qualidades, avaliadas ou a partir de um ponto de vista interno ou subjetivo, considerando a própria pessoa que a vive como sujeito autônomo, ou de um ponto de vista externo, a partir de uma perspectiva objetiva ou imparcial ${ }^{48,49}$.

Finalmente, o terceiro vetor de distinções está relacionado às abordagens éticas adotadas nas análises empreendidas nas pesquisas. Em vários artigos, é ressaltada a natureza pluralista do campo, expressa pelas diferentes concepções, teorias e métodos da bioética. Observa-se o predomínio do principialismo norte-americano de Tom L. Beauchamp e James F. Childress, formulado em seu livro Principles of Biomedical Ethics, publicado inicialmente em 1979, no qual são analisados os princípios da beneficência, não maleficência, autonomia e justiça. Além desta referência da bioética norte-americana, também é citada a Encyclopedia de Bioethics, editada pela primeira vez em 1978, por Warren T. Reich, e o bioeticista libertário H. Tristram Engelhard Jr., autor da obra Fundamentos da Bioética, publicada pela primeira vez em 1986. Da bioética europeia são utilizados predominatemente os trabalhos de Elio Sgreccia, Giovanni Berlinguer, Adélia Cortina, Diego Gracia, Guy Durant, Maurizio Mori e Peter Singer. Das abordagens latino-americanas, observadas nas pesquisas, destacam-se a Bioética de Intervenção de Volnei Garrafa e Dora Porto, a Bioética de Proteção de Fermin Roland Schramm e Michel Kottow, a Bioética Feminista e Antirracista de Fátima Oliveira, a Bioética Crítica de Inspiração Feminista de Débora Diniz e Dirce Guilhem, além dos trabalhos de Fernando Lolas, Ricardo Maliandi e Leo Pessini.

Saindo da especificidade da bioética, são mencionados com frequência livros e conceitos de filósofos políticos como John Rawls e Richard Rorty. E, em menor grau, Hannah Arendt, Charles Taylor, Julia Kristeva e Giorgio Agamben. Autores das Ciências Sociais não são muito utilizados. Encontramos alguns poucos artigos com reflexões a partir de autores tidos como referências clássicas nas Ciências Sociais, como Pierre Bourdieu, Luc Boltanski, Boaventura de Souza Santos, Ervin Goffman e, Philippe Ariés. Somente três artigos trazem reflexões a partir de Immanuel Kant, Michel Foucault, Jean Paul Sartre, Jean Piaget e John Stuart Mills.

\section{Análise da segunda etapa: usos da pesquisa qualitativa pelos artigos do campo da bioética}

Como pôde ser visto, menos de dez por cento dos estudos do campo da bioética na América Latina recorrem à pesquisa qualitativa como caminho para a produção de conhecimento. Há, no geral, pouca explicitação dos referenciais e recursos teórico-metodológicos empregados nos artigos como caminho para chegar às considerações apresentadas. Os artigos brasileiros são aqueles que mais expressam seus referenciais teórico-metodológicos. É recorrente a menção a livros utilizados tradicionalmente na Saúde Coletiva, como $\mathrm{O}$ desafio do conhecimento, de Minayo, O discurso do Sujeito Coletivo, organizado por Lefevre, Fundamentos da Metodologia Científica, de Lakatos, Análise de Conteúdo, de Bardin, e Introdução à Pesquisa em Ciências Sociais, de Triviños.

De forma geral, no conjunto dos artigos, a metodologia utilizada na maioria dos artigos aponta para o uso de técnicas diversificadas, sendo os questionários com perguntas fechadas e abertas o instrumento mais frequentemente utilizado. Predominam as entrevistas, em geral sob a forma semiestruturada, e a análise documental; poucos estudos basearam-se em etnografias ou realização de grupos focais (Tabela 2). As questões contidas nos instrumentos de pesquisa costumam ser apenas parcialmente apresentadas na parte de descrição dos métodos. Em caso de estudos que combinam métodos quantitativos e qualitativos, a análise dos dados tende a valorizar os dados numéricos e não problematizar questões por eles apontadas.

Os temas e objetivos propostos pelos artigos analisados podem ser contemplados a partir de quatro grandes temas, que dizem respeito ao modo

Tabela 2. Distribuição dos artigos com metodologia qualitativa, segundo as ferramentas metodológicas utilizadas.

\begin{tabular}{lc}
\hline \multicolumn{1}{c}{$\begin{array}{c}\text { Ferramentas } \\
\text { metodológicas }\end{array}$} & $\begin{array}{c}\text { Frequência } \\
\text { Absoluta }\end{array}$ \\
\hline Entrevistas semiestruturadas & 20 \\
Análise documental & 7 \\
Entrevistas + análise documental & 3 \\
Estudo etnográfico (observação & 2 \\
participante + entrevistas) & \\
Grupos focais + entrevistas & 1 \\
Total & $\mathbf{3 3}$ \\
\hline
\end{tabular}


como o campo tem sido construído nos últimos anos: 1) Caracterização e discussão da bioética enquanto campo e/ou discurso; 2) Pesquisas qualitativas que utilizam a bioética para discutir a formação em saúde; 3) Pesquisas qualitativas que discutem ética, assistência e prática clínica; 4) Pesquisas que utilizam a bioética para discutir a formulação de política de saúde (Quadro 2).

Um primeiro conjunto de trabalhos reúne textos preocupados com a construção do campo e de como o mesmo é visto/percebido na esfera da saúde. Constituem-se em poucos trabalhos, pois a maioria deles (como pudemos perceber anteriormente na análise mais ampla do material) não recorre a métodos de pesquisa qualitativa, com exceção dos aqui listados, que acabam propondo a discussão teórica do campo a partir de dados coletados em investigação. Os estudos que caminham nessa direção discutem valores a serem incorporados numa agenda de bioética, apontam valores de bioeticistas sobre princípios que regem sistemas de saúde, ou discutem respeito à garantia dos direitos de sujeitos de pesquisa, por exemplo.

Um segundo conjunto de trabalhos volta-se para uma área que parece concentrar grandes esforços acadêmicos: bioética e formação em saúde. Dentre os autores responsáveis por estes artigos, muitos são professores e pesquisadores em escolas das áreas da saúde. É sugestivo destacar o texto de Santiago e Palácios ${ }^{41}$ que estudaram temas éticos para a Enfermagem e observaram ampliação de artigos que se ocupam desses questionamentos a partir do ano de 1998. Dentre os objetos das pesquisas elencadas por nós nesse eixo estão, portanto, situações eticamente conflituosas vivenciadas por profissionais de saúde, bem como avaliações de conteúdos curriculares e aspectos variados na área de formação em saúde, dentre eles, o ensino da bioética.

Um terceiro conjunto de textos diz respeito à discussão de ética, assistência e prática clínica e reúne dados originados de pesquisa ou do cotidiano dos serviços de saúde, que se constituem, seja para os pesquisados, seja para os pesquisadores, em conflitos éticos. São exemplos estudos que contemplam as relações desenvolvidas entre profissionais de saúde e pacientes, ou as representações várias associadas a temas controversos, como eutanásia, aborto, reprodução assistida e outros. Estão também dentre os objetos de estudo questões psicossociais ligadas a doenças que envolvem estigma, como o HIV/AIDS e o câncer, e a relação dos profissionais de saúde com os pacientes. Também são encontrados aqui es- tudos centrados nos usuários de saúde e suas percepções sobre a assistência recebida. A maioria desses artigos demonstra que a dimensão ética no exercício profissional lida com situações corriqueiras da prática cotidiana. Para alguns autores desses estudos, os resultados dessas investigações podem estimular reflexões sobre os valores fundamentais das profissões e possibilitar repensar as práticas dos profissionais de saúde a partir da bioética. A observação participante e a etnografia foram eleitas como métodos centrais para alguns desses estudos.

Por fim, um quarto conjunto de artigos é representado por pesquisas que utilizam a bioética para discutir a formulação de política de saúde. São pesquisas trazem para o debate autores de outras áreas de saber e mostram como o campo das políticas de saúde pode se configurar num local de disputa de sentidos e saberes. Aqui se destacam artigos provenientes do campo das Ciências Sociais, e que se inscrevem em "temas bioéticos". São exemplos artigos que discutem, por exemplo, as novas tecnologias reprodutivas conceptivas ou a clonagem, temas que lidam, como os próprios artigos sugerem, com controvérsias. Nesses artigos são analisadas as concepções morais associadas aos debates em voga, incluindo pressupostos morais envolvidos na pesquisa científica.

Em relação ao tipo de população estudada pelos artigos (Tabela 3), predominaram os profissionais de saúde, isoladamente ou em conjunto com usuários de serviços de saúde; a seguir, encontram-se os usuários de serviços, os estudos documentais, os professores universitários e os estudantes de cursos de graduação e pós-graduação. Essa distribuição sugere a relevância, nos estudos qualitativos, de temas voltados para o trabalho em saúde, a percepção de usuários sobre esse trabalho e sobre temas impactantes sob o ponto de vista bioético e a questão da formação em saúde.

Outro aspecto a ser salientado é a menção à aprovação no Comitê de Ética em Pesquisa que, embora imperativa desde o ponto de vista da Saúde Coletiva, não se apresenta claramente em todos os textos mapeados. Parece-nos, no entanto, fundamental observar as limitações por vezes colocadas pela resolução $196 / 96^{50}$ às pesquisas qualitativas que se debruçam sobre os objetos da saúde. Esta resolução, instituída pela Comissão de Ética em Pesquisa (CONEP), visa regulamentar as pesquisas na área de saúde no Brasil, dirigindo-se indiscriminadamente, tanto ao que Oliveira ${ }^{51}$ chamou de "pesquisas em seres 
Quadro 2. Análise dos artigos por grande tema.

\begin{tabular}{|c|c|c|c|c|c|}
\hline $\mathrm{N}^{0}$ & Autor & $\begin{array}{l}\text { Bioética enquanto } \\
\text { campo e/ou discurso }\end{array}$ & $\begin{array}{l}\text { Formação } \\
\text { em Saúde }\end{array}$ & $\begin{array}{l}\text { Ética, assistência } \\
\text { e prática clínica }\end{array}$ & $\begin{array}{l}\text { Formulação das } \\
\text { políticas de saúde }\end{array}$ \\
\hline 1 & $\begin{array}{l}\text { Alvarez- } \\
\text { Diaz } \\
\mathrm{JA}^{6}\end{array}$ & & & $\begin{array}{l}\text { Alvarez-Díaz (2008) analisou as opiniões de } \\
\text { pacientes que recorreram a técnicas de } \\
\text { reprodução assistida complexas, relacionadas à } \\
\text { doação de gametas e embriões, no Peru, por } \\
\text { meio de "estudo transversal de bioética } \\
\text { descritiva, com metodologia qualitativa } \\
\text { etnográfica, mediante entrevista semi- } \\
\text { estruturada, aplicando análise de discurso ao } \\
\text { texto resultante". O autor observa que, entre as } \\
\text { duas, a doação de gametas é mais comentada e } \\
\text { aceita; a doação de embriões é um assunto } \\
\text { menos abordado e mais conflitivo entre os } \\
\text { casais, seja para doar ou para aceitar. }\end{array}$ & \\
\hline 2 & $\begin{array}{l}\text { Amorim } \\
\text { AG, } \\
\text { Souza } \\
\text { ECF }^{7}\end{array}$ & & & $\begin{array}{l}\text { Amorim e Souza objetivaram identificar } \\
\text { problemas éticos vivenciados na prática } \\
\text { profissional de cirurgiões-dentistas. }\end{array}$ & \\
\hline 3 & $\begin{array}{l}\text { Coli } \\
\text { RCP, } \\
\text { Anjos } \\
\text { MF, } \\
\text { Pereira } \\
\text { LL }^{8}\end{array}$ & & & $\begin{array}{l}\text { Coli e colaboradores, analisando a postura de } \\
\text { enfermeiros diante de ocorrências de erros em } \\
\text { procedimentos na UTI em um hospital privado } \\
\text { de São Paulo, mostram que estes profissionais } \\
\text { se percebem como pessoas que podem cometer } \\
\text { erros, ora comunicados, ora omitidos }\end{array}$ & \\
\hline 4 & $\begin{array}{l}\text { Costa } \\
\text { SIF, } \\
\text { Diniz } \\
\text { D }^{9}\end{array}$ & & & & $\begin{array}{l}\text { Costa e Diniz (2000) } \\
\text { analisaram matérias } \\
\text { extraídas dos } \\
\text { principais jornais } \\
\text { brasileiros sobre o } \\
\text { tema da clonagem. A } \\
\text { análise do material } \\
\text { teve como objetivo } \\
\text { mapear as concepções } \\
\text { morais associadas à } \\
\text { clonagem entre seres } \\
\text { humanos e identificar } \\
\text { alguns pressupostos } \\
\text { morais da pesquisa } \\
\text { cientifica com animais } \\
\text { não humanos e que, } \\
\text { segundo os autores, } \\
\text { foram reproduzidos } \\
\text { irrefletidamente pela } \\
\text { mídia. Os autores } \\
\text { concluíram que há } \\
\text { grande descompasso } \\
\text { entre as reflexões } \\
\text { bioéticas e a mídia } \\
\text { brasileira. }\end{array}$ \\
\hline
\end{tabular}




\begin{tabular}{|c|c|c|c|c|c|}
\hline \multicolumn{6}{|c|}{ Quadro 2. continuação } \\
\hline $\mathbf{N}^{\circ}$ & Autor & $\begin{array}{l}\text { Bioética enquanto } \\
\text { campo e/ou discurso }\end{array}$ & $\begin{array}{l}\text { Formação } \\
\text { em Saúde }\end{array}$ & $\begin{array}{l}\text { Ética, assistência } \\
\text { e prática clínica }\end{array}$ & $\begin{array}{c}\text { Formulação } \\
\text { das políticas } \\
\text { de saúde }\end{array}$ \\
\hline 5 & $\begin{array}{l}\text { Fagundes } \\
\text { MJD, } \\
\text { Soares } \\
\text { MGA, } \\
\text { Diniz } \\
\text { NM, } \\
\text { Pires JR, } \\
\text { Garrafa } \\
\mathrm{V}^{10} \text {. }\end{array}$ & & & $\begin{array}{l}\text { Fagundes et.al entrevistaram médicos para } \\
\text { examinar sua percepção sobre os efeitos da } \\
\text { propaganda de medicamentos, em sua atividade } \\
\text { profissional, e avaliaram peças publicitárias } \\
\text { sobre medicamentos. Para estes autores, os } \\
\text { resultados das investigaçôes podem contribuir } \\
\text { para repensar as práticas dos profissionais de } \\
\text { saúde a partir da bioética. }\end{array}$ & \\
\hline 6 & $\begin{array}{l}\text { Ferreira } \\
\text { FC, } \\
\text { Nichiata } \\
\text { LYI }^{11} \text {. }\end{array}$ & & & $\begin{array}{l}\text { Ferreira e Nichiata estudaram as motivações de } \\
\text { mulheres soropositivas para o HIV/AIDS na } \\
\text { revelação de seu status sorológico para } \\
\text { profissionais de saúde de uma equipe de PSF. } \\
\text { Encontraram, como resultado, uma forte } \\
\text { associação entre a revelação desta condição e a } \\
\text { confiança nos profissionais de saúde, traduzida, } \\
\text { por exemplo, na realização do diagnóstico pela } \\
\text { própria unidade, além da identificação de } \\
\text { "vínculo", "atenção" e "confiança" com a equipe } \\
\text { e serviço de saúde. }\end{array}$ & \\
\hline 7 & $\begin{array}{l}\text { Fortes } \\
\text { PAC }^{12}\end{array}$ & $\begin{array}{l}\text { Mostra, a partir de pesquisa } \\
\text { realizada com atores da } \\
\text { Sociedade Brasileira de } \\
\text { Bioética, que bioeticistas } \\
\text { brasileiros possuem distintas } \\
\text { interpretações sobre equidade }\end{array}$ & & & \\
\hline 8 & $\begin{array}{l}\text { Fortes } \\
\text { PAC }^{13}\end{array}$ & $\begin{array}{l}\text { Pesquisa realizada com } \\
\text { documentos e trabalho de } \\
\text { campo mostra que na Bolívia } \\
\text { há desconhecimento a } \\
\text { respeito de como garantir os } \\
\text { direitos dos sujeitos de } \\
\text { pesquisa, devido à quase } \\
\text { ausência e/ou do inadequado } \\
\text { funcionamento dos comitês } \\
\text { de ética em pesquisa no país }\end{array}$ & & & \\
\hline
\end{tabular}

humanos, como no caso da área biomédica", como às "pesquisas com seres humanos, que caracterizaria a situação da antropologia". Segundo Guerriero³, a resolução em questão "adota uma definição de pesquisa diferente da adotada pelos pesquisadores qualitativos". Esta questão tem sido assinalada pelos pesquisadores em programas de pós-graduação da área de Ciências Sociais e Humanas. Essa situação tem sido ainda mais difícil de gerir nos programas de pós-graduação em Saúde Coletiva, em que a penetração e legitimidade do modelo médico se fazem muito mais proeminentes, e a legitimidade das Ciências Humanas em Saúde ainda é assaz reduzida frente aos estudos biomédicos e epidemiológicos.

A maioria dos estudos é produzida dentro/a partir das universidades e, particularmente, no âmbito da pós-graduação. 
Quadro 2. continuação

\begin{tabular}{|c|c|c|c|c|c|}
\hline $\mathrm{N}^{\mathrm{o}}$ & Autor & $\begin{array}{l}\text { Bioética enquanto } \\
\text { campo e/ou discurso }\end{array}$ & $\begin{array}{l}\text { Formação } \\
\text { em Saúde }\end{array}$ & $\begin{array}{l}\text { Ética, assistência } \\
\text { e prática clínica }\end{array}$ & $\begin{array}{c}\text { Formulação } \\
\text { das políticas } \\
\text { de saúde }\end{array}$ \\
\hline 9 & $\begin{array}{l}\text { Fracapani } \mathrm{M}, \\
\text { Fazio } \mathrm{M}^{14}\end{array}$ & & $\begin{array}{l}\text { Fracapani e Fazio (2008) } \\
\text { avaliaram a } \\
\text { aprendizagem de um } \\
\text { curso de pós-graduação } \\
\text { interdisciplinar, } \\
\text { envolvendo os alunos na } \\
\text { avaliação e confecção de } \\
\text { um portfólio. }\end{array}$ & & \\
\hline 10 & $\begin{array}{l}\text { Garbin CAS, } \\
\text { Gonçalves } \\
\text { PE, Garbin } \\
\text { AJI, Moimaz } \\
\text { SAS }^{15} \text {. }\end{array}$ & & & & \\
\hline 11 & $\begin{array}{l}\text { Garrafa V, } \\
\text { Albuquerque } \\
\mathrm{MC}^{16} \text {. }\end{array}$ & & & $\begin{array}{l}\text { Para Garrafa e Albuquerque }{ }^{1} \text {, que } \\
\text { realizaram pesquisa com } \\
\text { intensivistas, a bioética poderia } \\
\text { proporcionar à ética médica meios } \\
\text { para estimular reflexões sobre os } \\
\text { valores fundamentais da profissão. }\end{array}$ & \\
\hline 12 & $\begin{array}{l}\text { Gonçalves } \\
\text { PE, Saliba } \\
\text { Garbin CA, } \\
\text { Isper Garbin } \\
\text { AJ, Adas } \\
\text { Saliba } \mathrm{N}^{17} \text {. }\end{array}$ & & $\begin{array}{l}\text { Gonçalves et. al (2010) } \\
\text { realizaram analise } \\
\text { qualitativa do conteúdo } \\
\text { ministrado pela } \\
\text { disciplina de Bioética em } \\
\text { Faculdades de } \\
\text { Odontologia Brasileiras, } \\
\text { coletando dados por } \\
\text { meio de questionários } \\
\text { semi-estrutruados } \\
\text { enviados por email e } \\
\text { correspondência. }\end{array}$ & & \\
\hline 13 & $\begin{array}{l}\text { Griboski RA, } \\
\text { Guilhem } D^{18} \text {. }\end{array}$ & & & & \\
\hline 14 & Guerra RA ${ }^{19}$. & & $\begin{array}{l}\text { Guerra (2006) discutiu a } \\
\text { relevância da bioética } \\
\text { como disciplina no } \\
\text { currículo de formação da } \\
\text { graduação em } \\
\text { odontologia na } \\
\text { Argentina, a partir de } \\
\text { uma metodologia que } \\
\text { combinou pesquisa na } \\
\text { internet, analise de } \\
\text { textos, currículos e } \\
\text { planos, e entrevistas com } \\
\text { autoridades do campo da } \\
\text { Educação. }\end{array}$ & & \\
\hline
\end{tabular}




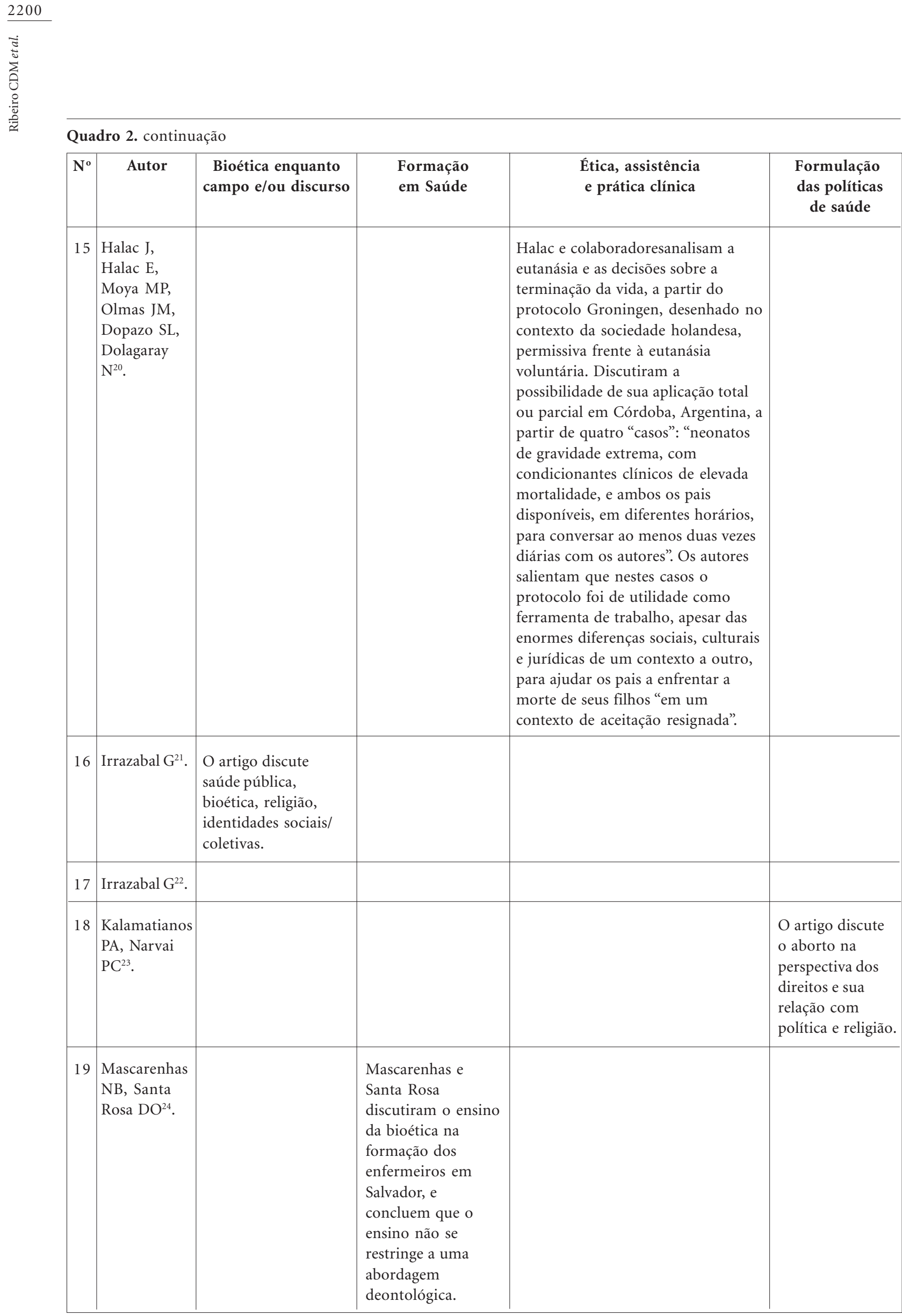


Quadro 2. continuação

\begin{tabular}{|c|c|c|c|c|c|}
\hline $\mathrm{N}^{\circ}$ & Autor & $\begin{array}{c}\text { Bioética enquanto } \\
\text { campo e/ou discurso }\end{array}$ & $\begin{array}{l}\text { Formação } \\
\text { em Saúde }\end{array}$ & $\begin{array}{l}\text { Ética, assistência } \\
\text { e prática clínica }\end{array}$ & $\begin{array}{c}\text { Formulação } \\
\text { das políticas } \\
\text { de saúde }\end{array}$ \\
\hline 20 & $\begin{array}{l}\text { Mashiri Z, } \\
\text { Elizabeth } C^{25} \text {. }\end{array}$ & & & & \\
\hline 21 & $\begin{array}{l}\text { Mondragon } \\
\text { L, Monroy Z, } \\
\text { Ito ME, } \\
\text { Medina- } \\
\text { Mora } \mathrm{ME}^{26} \text {. }\end{array}$ & & & $\begin{array}{l}\text { Preocupações similares, que dizem } \\
\text { respeito à relação profissional de } \\
\text { saúde-paciente, podem ser lidas em } \\
\text { Mondragón e colaboradores }{ }^{2} \text { que } \\
\text { buscaram conhecer as disjunções } \\
\text { entre os princípios de beneficência } \\
\text { e autonomia apresentados na } \\
\text { relação médico-paciente durante a } \\
\text { terapêutica do intento do suicídio. } \\
\text { Os autores realizaram pesquisa em } \\
\text { dois hospitais psiquiátricos da } \\
\text { Cidade do México, partindo de } \\
\text { referenciais teórico-metodológicos } \\
\text { da Psicologia Social, e abordando } \\
\text { três sujeitos com intento suicida e } \\
\text { três psiquiatras que deles tratavam. }\end{array}$ & \\
\hline 22 & $\begin{array}{l}\text { Peláez F, } \\
\text { Rosa } Z^{27} \text {. }\end{array}$ & & $\begin{array}{l}\text { Peláez(2009) discutiu } \\
\text { imaginário e } \\
\text { compromissos } \\
\text { cotidianos com a ética } \\
\text { do cuidado e a bioética } \\
\text { entre graduandos de } \\
\text { uma universidade de } \\
\text { ciências jurídicas e } \\
\text { sociais. }\end{array}$ & & \\
\hline 23 & $\begin{array}{l}\text { Santiago } \\
\text { MMA, } \\
\text { Palácios } \mathrm{M}^{28} \text {. }\end{array}$ & & $\begin{array}{l}\text { É sugestivo destacar o } \\
\text { texto de Santiago e } \\
\text { Palácios que estudaram } \\
\text { temas éticos para a } \\
\text { Enfermagem e } \\
\text { observaram ampliação } \\
\text { de artigos que se ocupam } \\
\text { de questionamentos } \\
\text { éticos a partir do ano de } \\
1998 .\end{array}$ & & \\
\hline 24 & $\begin{array}{l}\text { Schonhaut- } \\
\text { Berman L, } \\
\text { Millan- } \\
\text { Klusse T, } \\
\text { Hanne- } \\
\text { Altermatt } \\
\mathrm{C}^{29} \text {. }\end{array}$ & & & & \\
\hline 25 & $\begin{array}{l}\text { Selli L, } \\
\text { Garrafa } V^{30} \text {. }\end{array}$ & & & & \\
\hline
\end{tabular}


Quadro 2. continuação

\begin{tabular}{|c|c|c|c|c|c|}
\hline $\mathrm{N}^{\circ}$ & Autor & $\begin{array}{c}\text { Bioética enquanto } \\
\text { campo e/ou discurso }\end{array}$ & $\begin{array}{l}\text { Formação } \\
\text { em Saúde }\end{array}$ & $\begin{array}{l}\text { Ética, assistência } \\
\text { e prática clínica }\end{array}$ & $\begin{array}{c}\text { Formulação das políticas } \\
\text { de saúde }\end{array}$ \\
\hline 26 & $\begin{array}{l}\text { Selli L, } \\
\text { Garrafa V, } \\
\text { Junges JR }{ }^{31} \text {. }\end{array}$ & $\begin{array}{l}\text { analisaram uma } \\
\text { atividade voluntária } \\
\text { em um hospital e } \\
\text { propõem, a partir daí, } \\
\text { a "solidariedade } \\
\text { crítica" como valor a } \\
\text { ser incorporado na } \\
\text { agenda bioética do } \\
\text { século XXI. }\end{array}$ & & & \\
\hline 27 & $\begin{array}{l}\text { Silva, RP, } \\
\text { Ribeiro } \\
\text { VMB }^{32} .\end{array}$ & & & & \\
\hline 28 & $\begin{array}{l}\text { Tamanini } \\
\mathrm{M}^{33}\end{array}$ & & & & $\begin{array}{l}\text { O artigo de Tamanini }{ }^{37} \text {, sobre novas } \\
\text { tecnologias reprodutivas conceptivas, } \\
\text { lida, como o próprio título aponta, com } \\
\text { bioética e controvérsias. Após revisão } \\
\text { exaustiva dos conteúdos da ética/bioética } \\
\text { e a deontologia médica, aponta que o } \\
\text { debate vem mudando ao longo do } \\
\text { tempo. A autora demonstra alguns } \\
\text { princípios éticos/biomédicos do agir } \\
\text { médico encontrados em dados coletados } \\
\text { em pesquisa com casais heterossexuais } \\
\text { que fizeram reprodução assistida e com } \\
\text { médicos especialistas em reprodução } \\
\text { humana na região Sul do Brasil. } \\
\text { Irrazábal }{ }^{4} \text { aborda a participação de } \\
\text { grupos católicos especializados em } \\
\text { bioética e biodireito nos debates } \\
\text { parlamentares sobre aborto não punido } \\
\text { em Buenos Aires”, no final de } 2008 \text {. A } \\
\text { autora parte de observações realizadas } \\
\text { nas audiências, além de documentos das } \\
\text { sessões publicadas pela Assembléia } \\
\text { Legislativa da Cidade de Buenos Aires. }\end{array}$ \\
\hline 29 & $\begin{array}{l}\text { Taquette } \\
\text { SR, Rego S, } \\
\text { Schramm } \\
\text { SR, Soares } \\
\text { LL, } \\
\text { Carvalho } \\
\text { SV }^{34} \text {. }\end{array}$ & & $\begin{array}{l}\text { Taquette et al. } \\
\text { estudaram } \\
\text { situações } \\
\text { eticamente } \\
\text { conflituosas } \\
\text { vivenciadas por } \\
\text { estudantes de } \\
\text { medicina com a } \\
\text { finalidade de } \\
\text { subsidiar o } \\
\text { currículo com } \\
\text { novos conteúdos } \\
\text { de bioética. }\end{array}$ & & \\
\hline
\end{tabular}




\begin{tabular}{|c|c|c|c|c|c|}
\hline $\mathrm{N}^{\mathrm{o}}$ & Autor & $\begin{array}{l}\text { Bioética enquanto } \\
\text { campo e/ou discurso }\end{array}$ & $\begin{array}{l}\text { Formação } \\
\text { em Saúde }\end{array}$ & $\begin{array}{l}\text { Ética, assistência } \\
\text { e prática clínica }\end{array}$ & $\begin{array}{c}\text { Formulação das } \\
\text { políticas } \\
\text { de saúde }\end{array}$ \\
\hline 30 & $\begin{array}{l}\text { Vasconcelos } \\
\text { FAG }^{35} \text {. }\end{array}$ & & & & \\
\hline 31 & Wainer $\mathrm{R}^{36}$. & & & $\begin{array}{l}\text { Wainer parte da Antropologia para analisar a } \\
\text { construção profissional paliativista ao redor } \\
\text { da dignidade, a partir da perspectiva dos } \\
\text { integrantes de uma equipe de cuidados } \\
\text { paliativos de um hospital de adultos } \\
\text { especializado em enfermidades oncológicas. } \\
\text { Após pesquisa etnográfica sinaliza que "a } \\
\text { dignidade ao final da vida está estreitamente } \\
\text { relacionada às concepções sociais e } \\
\text { profissionais sobre a morte (...), que é em } \\
\text { última instância uma construção social". }\end{array}$ & \\
\hline 32 & $\begin{array}{l}\text { Zoboli } \\
\text { ELCP }^{37}\end{array}$ & & & $\begin{array}{l}\text { Zoboli estudou problemas éticos vividos por } \\
\text { enfermeiros na atenção básica, a partir de } \\
\text { "estudo de ética descritiva, empírico, } \\
\text { qualitativo" em PSF de São Paulo. A maioria } \\
\text { desses artigos demonstra que a dimensão ética } \\
\text { no exercício profissional lida com situações } \\
\text { corriqueiras da prática cotidiana. }\end{array}$ & \\
\hline 33 & $\begin{array}{l}\text { Zoboli } \\
\text { ELCP, } \\
\text { Fortes } \\
\text { PAC }^{38}\end{array}$ & & & $\begin{array}{l}\text { Zoboli e Fortes estudaram problemas éticos } \\
\text { entre enfermeiros e médicos que atuam no } \\
\text { PSF em São Paulo. }\end{array}$ & \\
\hline
\end{tabular}

Tabela 3. Distribuição dos artigos com metodologia qualitativa, segundo a população estudada.

\begin{tabular}{lc}
\hline \multicolumn{1}{c}{$\begin{array}{c}\text { População } \\
\text { estudada }\end{array}$} & $\begin{array}{c}\text { Frequência } \\
\text { Absoluta }\end{array}$ \\
\hline Profissionais de Saúde & 8 \\
Usuários de Serviços de Saúde & 5 \\
Professores Universitários & 4 \\
Usuários + Profissionais de Saúde & 3 \\
Voluntários atuantes em Instituições de & 2 \\
Saúde & \\
Estudantes de Cursos de Graduação & 1 \\
Estudantes de Cursos de Pós-Graduação & 1 \\
Estudantes de Graduação + Estudantes & 1 \\
de Pós & \\
Professores Universitários + Estudantes & 1 \\
Graduação & 7 \\
Não se aplica (análise documental) & 33 \\
Total & \\
\hline
\end{tabular}

Nos artigos produzidos no Brasil, 25 fazem parte do quadro de universidades públicas; 3 de universidades particulares; 4 de centros de pesquisa e 3 autores são ligados a instâncias/agências governamentais. Nos estudos produzidos fora do Brasil, dez dos autores são ligados a universidades; e somente um se identifica como membro de um Hospital Privado. Cabe ressaltar que aqueles que parecem estar fora da universidade, como primeiro local de trabalho, em geral possuem parceiros, colaboradores ou orientadores que são apresentados como coautores. O predomínio da academia na produção desses estudos é claro e responde às características históricas da produção dos campos da Bioética e dos Estudos Qualitativos em Saúde na América Latina. Nos outros países da América Latina e do Caribe, onde não existe a Saúde Coletiva enquanto disciplina formalmente instituída, os estudos se relacionam primariamente ao mundo dos serviços de saúde 
e do cotidiano de decisão sobre casos "difíceis" ou desafiadores. Mas a influência ideológica da Saúde Coletiva é de grande importância já que, como mostramos abaixo, vai definir temáticas, leituras, argumentos e autores utilizados.

Em relação à formação profissional, são poucos os autores - talvez por política editorial das revistas - que expressam sua graduação. Listamos três odontólogos, três médicos, dois sociólogos, um filósofo e cinco enfermeiras. A grande maioria de autores tem títulos de mestre ou doutor. É interessante salientar que nos artigos em espanhol figuram três estudos com pesquisadoras ligadas à Igreja Católica, sendo uma socióloga e uma missionária.

\section{Conclusões}

A revisão e posterior análise dos textos permitiunos compreender a produção do campo da bioética como plural e diversificada, abarcando diversos temas e demarcando uma área interdisciplinar. Essa interdisciplinaridade é marca constitutiva do campo da bioética, portanto, característica apriorística e desejada pelos seus atores.

O conjunto dos textos analisados nos permite afirmar ainda que a maior parte da produção deste campo advém de artigos teóricos, reflexões geradas a partir de investigações quantitativas e questões clínicas, evidenciando, do ponto de vista dos marcos disciplinares, forte influência da Filosofia, e ainda forte adesão da Medicina, seguida por outras áreas da saúde, com destaque também para a Epidemiologia.

Os artigos baseados em pesquisas qualitativas constituem a menor parte da produção do campo da bioética, ainda que este cenário esteja sendo gradualmente modificado. Estes textos que utilizam métodos de pesquisa qualitativa podem ser agrupados, a partir de suas aproximações temáticas, em quatro grandes temas [1) Caracterização e discussão da bioética enquanto campo e/ou discurso, 2) Pesquisas qualitativas que utilizam a bioética para discutir a formação em saúde, 3) Pesquisas qualitativas que discutem ética, assistência e prática clínica; 4) Pesquisas que utilizam a bioética para discutir a formulação de política de saúde].

$\mathrm{O}$ conjunto de artigos qualitativos encontrados nestes grandes temas mostra o emprego de variadas (e, por vezes, imprecisas) estratégias metodológicas. Os dados mostram, por um lado, pouca utilização de metodologias qualitativas nas pesquisas realizadas no campo da bioética, uma relativa e ainda tímida aproximação de pesquisadores das Ciências Sociais ao campo da bioética e, por outro lado, certa imprecisão quanto ao uso de métodos pelo conjunto dessas pesquisas.

Os estudos qualitativos têm uma longa trajetória nas Ciências Sociais, mais expressivamente para a antropologia, dada a centralidade que tem o trabalho de campo para esta disciplina ${ }^{52-55}$. No entanto, a contribuição da antropologia para as investigações qualitativas na área da saúde só tem sido valorizada em décadas mais recentes, fato que pode explicar o pouco debate dos artigos aqui encontrados, com algumas exceções, com esta literatura ${ }^{55}$. Como mostra Minayo ${ }^{4}$, a antropologia pode trazer importantes subsídios à produção de conhecimento sobre saúde, à medida que contribui para relativizar conceitos biomédicos, compreender a estrutura dos mecanismos terapêuticos, evidenciar relações entre saúde/doença e realidade social e contextualizar os sujeitos na abordagem dos processos saúde/doença. Nesse sentido, sugerimos que as Ciências Sociais, através do seu variado instrumental teórico-metodológico, podem assumir um papel relevante no aprofundamento dos debates trazidos pelas investigações no campo da bioética.

\section{Colaboradores}

CDM Ribeiro, I Maksud, LBL Claro e JW Un participaram da concepção do texto, coleta e análise de dados, e redação do texto. 


\section{Referências}

1. Sánchez APM. Perspectiva de La bioética en América. Rev Hum Med 2010; 10(1):1727-8120.

2. Oliveira AAS, Villapouca KC, Barroso W. Perspectivas epistemológicas da bioética brasileira a partir da teoria de Thomas Kuhn. Rev Bras Bioet 2005; 1(4):363-385.

3. Guerriero ICZ. Aspectos éticos das pesquisas qualitativas em saúde [tese]. São Paulo: Universidade de São Paulo; 2006.

4. Minayo MCS. Contribuições da antropologia para pensar e fazer saúde. In: Campos GWS, Minayo MCS, Akerman M, Drumond Júnior M, Carvalho YM, organizadores. Tratado de Saúde Coletiva. São Paulo, Rio de Janeiro: Fiocruz, Hucitec; 2009. p.189-218.

5. Guerriero ICZ, Dallari SG. The need for adequate ethical guidelines for qualitative health research. Cien Saude Colet 2008; 13(2):303-311.

6. Alvarez-Diaz JA. Un estudio exploratorio sobre la donación hipotética de embriones humanos en Chile. An Med Interna (Madrid) 2007; 24(12):579-

7. Amorim AG, Souza ECF. Problemas éticos vivenciados por dentistas: dialogando com a bioética para ampliar o olhar sobre o cotidiano da prática profissional. Cien Saude Colet 2010; 15(3):869-878.

8. Coli RCP, Anjos MF, Pereira LL. The Attitudes of Nurses from an Intensive Care Unit in the Face of Errors: an Approach in Light of Bioethics. Rev Latino-Am Enfermagem 2010; 18(3):324-330.

9. Costa SIF, Diniz D. Mídia, clonagem e bioética. Cad Saude Publica 2000; 16(1):155-162.

10. Fagundes MJD, Soares MGA, Diniz NM, Pires JR, Garrafa V. Análise bioética da propaganda e publicidade de medicamentos. Cien Saude Colet 2007; 12(1):221-229.

11. Ferreira FC, Nichiata LYI. Mulheres vivendo com aids e os profissionais do Programa Saúde da Família: revelando o diagnóstico. Rev Esc Enferm 2008; 42(3):483-489.

12. Fortes PAC. A equidade no sistema de saúde na visão de bioeticistas brasileiros. Rev Assoc Med Bras 2010; 56(1):47-50

13. Fortes PAC. Bioeticistas brasileiros e os princípios da universalidade e da integralidade no SUS. Rev Saude Publica 2009; 43(6):1054-1058.

14. Fracapani M, Fazio M. El portafolio como estrategia de evaluación en carreras de posgrado inter y transdisciplinarias. Acta Bioeth 2008; 14(1):68-73.

15. Garbin CAS, Gonçalves PE, Garbin AJI, Moimaz SAS. Evaluación de las metodologías de enseñanza-aprendizaje de la bioética en las facultades de odontología brasileñas. Educ Méd 2009; 12(4):231237.

16. Garrafa V, Albuquerque MC. Enfoque bioético de lacomunicación en la relación médico-paciente en las unidades de terapia intensiva pediátricas. Acta Bioeth 2001; 7(2):355-367.

17. Gonçalves PE, Saliba Garbin CA, Isper Garbin AJ Adas Saliba N. Análise qualitativa do conteúdo ministrado na disciplina de bioética nas faculdades de odontologia brasileiras. Acta Bioeth 2010; 16(1):
18. Griboski RA, Guilhem D. Mulheres e profissionais de saúde: o imaginário cultural na humanização ao parto e nascimento. Texto Contexto - Enferm 2006; 15(1):107-114.

19. Guerra RA. Bioética en la malla curricular de odontología. Acta Bioeth 2006; 12(1):49-54.

20. Halac J, Halac E, Moya MP, Olmas JM, Dopazo SL, Dolagaray N. Bioética perinatal: ¿Eutanasia o decisiones sobre terminación de la vida?: Análisis del Protocolo de Groningen. Arch Argent Pediatr 2009; 107(6):520-526.

21. Irrazabal G. Bioética y catolicismo: dificultades en torno a la constitución de una identidad colectiva. Relig Soc 2010; 30(1):101-116.

22. Irrazabal G. El derecho al aborto en discusión: la intervención de grupos católicos en la comisión de salud de la legislatura de la ciudad de Buenos Aires. Sociologias 2010; 12(24):308-336.

23. Kalamatianos PA, Narvai PC. Aspectos éticos do uso de produtos fluorados no Brasil: uma visão dos formuladores de políticas públicas de saúde. Cien Saude Colet 2006; 11(1):63-69.

24. Mascarenhas NB, Santa Rosa DO. Ensino da bioética na formação do enfermeiro: interface com a bibliografia adotada. Acta Paul Enferm 2010; 23(3): 392-398

25. Mashiri Z, Elizabeth C. Los comités de ética de investigación biomédica y psicosocial en Bolivia. Acta Bioeth 2010; 16(1):87-91

26. Mondragon L, Monroy Z, Ito ME, Medina-Mora ME. Disyuntivas en las concepciones sobre autonomía y beneficencia que afectan la terapéutica del intento suicida. Acta Bioeth 2010; 16(1):77-86.

27. Peláez F, Rosa Z. La bioética: ética del cuidado de la vida y la salud para el desarrollo humano. Hacia Promoc Salud 2009; 14(2):76-93.

28. Santiago MMA, Palácios M. Temas éticos e bioéticos que inquietaram a Enfermagem: publicações da REBEn de 1970-2000. Rev Bras Enferm 2006; 59(3):349-353.

29. Schonhaut-Berman L, Millan-Klusse T, Hanne-Altermatt C. Competencias transversales en la formación de especialistas en pediatría, Universidad de Chile. Educ Méd 2009; 12(1):33-41.

30. Selli L, Garrafa V. Bioética, solidariedade crítica e voluntariado orgânico. Rev Saude Publica 2005; 39(3): 473-478.

31. Selli L, Garrafa V, Junges JR. Beneficiários do trabalho voluntário: uma leitura a partir da bioética. Rev Saude Publica 2008; 42(6):1085-1089.

32. Silva RP, Ribeiro VMB. Inovação curricular nos cursos de graduação em medicina: o ensino da bioética como uma possibilidade. Rev Bras Educ Med 2009; 33(1):134-143.

33. Tamanini M. Novas tecnologias reprodutivas conceptivas: bioética e controvérsias. Rev Estud Fem 2004; 12(1):73-107.

34. Taquette SR, Rego S, Schramm SR, Soares LL, Carvalho SV. Situações eticamente conflituosas vivenciadas por estudantes de medicina. Rev Assoc Med Bras 2005; 51(1):23-28. 
35. Vasconcelos FAG. Fome, solidariedade e ética: uma análise do discurso da Ação da Cidadania contra a Fome, a Miséria e pela Vida. Hist Cienc Saude-Manguinhos 2004; 11(2):259-277.

36. Wainer R. Acompañando a la gente en el último momento de su vida: reflexiones en torno a la construcción paliativista de la dignidad en el final de la vida. Runa 2011; 28(28):111-140.

37. Zoboli ELCP. Enfermeiros e usuários do Programa Saúde da Família: contribuições da bioética para reorientar esta relação profissional. Acta Paul Enferm 2007; 20(3):316-320

38. Zoboli ELCP, Fortes PAC. Bioética e atenção básica: um perfil dos problemas éticos vividos por enfermeiros e médicos do Programa Saúde da Família, São Paulo, Brasil. Cad Saude Publica 2004; 20(6):1690-1699.

39. Irrazabal G. Bioética y catolicismo: dificultades en torno a la constitución de una identidad colectiva. Relig Soc 2010; 30(1):101-116.

40. Kottow M. Bioetica: especialidad académica o movimiento social. Rev Bras Bioet 2007; 3(3):328-343.

41. Santiago MMA, Palacios M. Temas éticos e bioéticos que inquietaram a Enfermagem: publicacões da REBEn de 1970-2000. Rev Bras Enferm 2006; 59(3):349-353.

42. Rawls J. Uma teoria da justiça. São Paulo: Martins Fontes; 1997

43. Burg WV, Willigenburg T. Introduction. In: Burg W, Willigenburg T, editors. Reflective Equilibrium. Essays in honour of Robert Heeger. Dordrecht, Boston, London: Kluwer Academic Publishers; 1998. p. 1-25.

44. Daniels N. Justice and justification. Reflective equilibrium in theory and practice. New York: Cambridge University Press; 1996.

45. Kleinman A. Ethics and experience: an anthropological approach. In: Anand S, Peter F, Sen A, editors. Public health, ethics, and equity. New York: Oxford University Press; 2009. p. 263-268.
46. Mascarenhas NB, Santa Rosa DO. Ensino da Bioética na formação do enfermeiro: interface com a bibliografia adotada. Acta Paul Enferm 2010; 23(3):392-398.

47. Almeida JLT, Schramm FR. Paradigma shift, metamorphosis of medical ethics, and the rise of bioethics. Cad Saude Publica 1999; 15(Supl. 1):15-25.

48. Mori M. A bioética: sua natureza e história. Humanidades 1994; 9(4):333-341

49. Sen A. Health achievement a equity: external and internal perspectives. In: Anand S, Peter F, Sen A, editors. Public health, ethics, and equity. New York: Oxford University Press; 2009. p. 263-268.

50. Brasil. Ministério da Saúde (MS). Conselho Nacional de Saúde. Resolução no 196 de 10 de outubro de 1996. Diretrizes e Normas Regulamentadoras de Pesquisas Envolvendo Seres Humanos. Diário Oficial da União 1996; 16 out.

51. Oliveira LRC. Pesquisa em versus pesquisas com seres humanos. In: Víctora C, Oliven RG, Maciel ME, Oro AP, organizadores. Antropologia e Ética. O debate atual no Brasil. Rio de Janeiro: ABA, Editora da Universidade Federal Fluminense; 2004. p. 33-44.

52. Zaluar A. Introdução. In: Zaluar A, organizadora. Desvendando máscaras sociais. Rio de Janeiro: Livraria Francisco Alves Editora; 1990. p. 9-38.

53. Diniz D. Ética na pesquisa em ciências humanas: novos desafios. Cien Saude Colet 2008; 13(2):417-426.

54. Giumbelli E. Para além do "trabalho de campo": reflexões supostamente inowskianas. Rev Bras Ci Soc 2002; 17(48):91-107.

55. Sarti CA. A difficult dialogue. Cien Saude Colet 2008; 13(2):315-318.

Artigo apresentado em 14/06/2013

Aprovado em 23/09/2013

Versão final apresentada em 02/10/2013 